\title{
PENGEMBANGAN TES HASIL BELAJAR IPS DAN KUESIONER MOTIVASI BELAJAR SISWA KELAS IV SD
}

\author{
L.E. Darmayanti ${ }^{1}$, N.K. Suarni ${ }^{2}$, I.B.P. Arnyana ${ }^{3}$ \\ ${ }^{123}$ Program Studi Pendidikan Dasar \\ Universitas Pendidikan Ganesha \\ Singaraja, Indonesia \\ e-mail: ekadarmayanti15@gmail.com ${ }^{1}$, niketut.suarni@undiksha.ac.id ${ }^{2}$, \\ putu.arnyana@undiksha.ac.id ${ }^{3}$
}

\begin{abstract}
Abstrak
Penelitian ini bertujuan untuk mengetahui dan mendeskripsikan validitas dan reliabilitas tes hasil belajar IPS dengan kuesioner motivasi belajar siswa kelas IV SD. Penelitian ini merupakan jenis penelitian pengembangan atau Research and Development (R\&D) melalui empat tahapan yaitu pendefinisian, perencanaan, pengembangan dan penyebarluasan. Subyek penelitian ini adalah guru kelas IV SD dan dosen. Data yang dikumpulkan adalah validitas tes hasil belajar IPS, validitas kuesioner motivasi belajar kelas IV SD, reliabilitas tes hasil belajar IPS dan reliabilitas kuesioner motivasi belajar kelas IV SD. Validitas tes hasil belajar IPS dan motivasi belajar kelas IV SD dianalisis menggunakan rumus CVR dan CVI, Reliabilitas tes hasil belajar IPS dianalisis menggunakan rumus KR 20 sedangkan reliabilitas motivasi belajar kelas IV SD menggunakan rumus alfa cronbach. Hasil penelitian menunjukkan bahwa: Pertama, validitas tes hasil belajar IPS memiliki validity index sebesar 0,60 yang berarti memiliki kriteria validitas tinggi. Kedua, validitas kuesioner motivasi belajar juga memiliki validity index sebesar 0,60 yang berarti memiliki kriteria validitas tinggi. Ketiga, reliabilitas tes hasil belajar IPS memiliki reliabel sebesar 0,85 yang berarti memiliki kriteria reliabilitas sangat tinggi. Keempat, reliabilitas kuesioner motivasi belajar memiliki reliabel sebesar 0,65 yang berarti memiliki kriteria reliabilitas tinggi.
\end{abstract}

Kata kunci: IPS; Motivasi Belajar

\begin{abstract}
This study aims to determine and describe the validity and reliability of social studies learning test results with a learning motivation questionnaire for fourth grade elementary school students. This research is a type of research and development $(R \& D)$ through four stages, namely the definition, planning, development and dissemination. The subjects of this study were fourth grade elementary school teachers and lecturers. The data collected were the validity of the Social Studies learning achievement test, the validity of the fourth grade elementary school motivation, the reliability of the social studies achievement test and the reliability of the fourth grade elementary school motivation. The validity of social studies learning outcomes tests and class IV elementary school motivation were analyzed using the CVR and CVI formulas, the reliability of social studies learning outcomes tests were analyzed using the KR 20 formula while the reliability of learning motivation of grade IV elementary schools used the Cronbach alpha formula. The results showed that: First, the validity of the IPS learning outcomes test had a validity index of 0.60 which means it had high validity criteria. Second, the validity of the learning motivation questionnaire also has a validity index of 0.60 which means it has high validity criteria. Third, the reliability of the Social Studies learning outcomes test has a reliability of 0.85 which means it has very high reliability criteria. Fourth, the reliability of the learning motivation questionnaire has a reliability of 0.65 which means it has high reliability criteria
\end{abstract}

Keywords: IPS; Motivation to Learn 


\section{PENDAHULUAN}

Pendidikan merupakan sarana penting untuk meningkatkan kualitas sumber daya manusia (SDM) dalam menjamin keberlangsungan pembangunan suatu bangsa. Hal ini jelas dalam Mukadimah Undang-undang Dasar 1945 yang menyuratkan dan menyiratkan bahwa salah satu tujuan nasional Indonesia adalah mencerdaskan kehidupan bangsa. Dalam hal ini mencerdaskan kehidupan bangsa diartikan secara mendalam dan menyeluruh yaitu menjadikan manusia sebagai manusia seutuhnya yang beriman dan bertaqwa terhadap Tuhan Yang Maha Esa dan berbudi pekerti luhur, memiliki pengetahuan dan keterampilan, sehat jasmani dan rohani, kepribadian yang mantap dan mandiri serta bertanggung jawab kemasyarakatan dan kebangsaan.

Pendidikan yang berkualitas akan berpengaruh pada kemajuan diberbagai bidang. Sejalan dengan isi pendidikan nasional adalah "terwujudnya sistem pendidikan sebagai pranata sosial yang kuat dan berwibawa untuk memberdayakan semua warga Indonesia berkembang menjadi manusia yang berkualitas, sehingga mampu dan proaktif menjawab tantangan zaman yang selalu berubah" (Rusman, 2011:03). Kesadaran tentang arti pentingnya pendidikan mendorong berbagai pihak untuk melakukan berbagai upaya agar perkembangan dunia pendidikan semakin maju, seperti anggaran pendidikan, pengembangan kurikulum, peningkatan kompetensi guru, peningkatan sarana dan prasarana lainnya. Hal ini dilakukan agar pembelajaran yang diharapkan adalah suatu proses yang dapat mengembangkan potensi-potensi siswa secara menyeluruh dan terpadu (Ainurrahman, 2011). Oleh karena itu, dalam pembelajaran guru tidak hanya dituntut menyampaikan materi pembelajaran akan tetapi, harus mampu mendorong tumbuhnya keaktifan dan kreativitas setiap siswa.

Perubahan kurikulum pada Kurikulum 2013 yaitu menuntut semua jenjang yang dilaksanakan dengan menggunakan pendekatan ilmiah. Proses pembelajaran harus menyentuh tiga ranah, yaitu sikap, pengetahuan, dan keterampilan. Dalam proses pembelajaran berbantuan pendekatan ilmiah, ranah sikap menggamit transformasi substansi atau materi ajar agar peserta didik tahu tentang "mengapa". Ranah keterampilan menggamit transformasi substansi atau materi ajar agar peserta didik tahu tentang "bagaimana". Ranah pengetahuan menggamit transformasi substansi atau materi ajar agar peserta didik tahu tentang "apa". Peningkatan dan keseimbangan antara kemampuan untuk menjadi manusia yang baik (soft skills) dan manusia yang memiliki kecakapan dan pengetahuan untuk hidup secara layak (hard skills) dari peserta didik yang meliputi aspek kompetensi sikap, keterampilan, dan pengetahuan. Perubahan pada proses pembelajaran yang dimaksudkan di atas mencakup: a) berorientasi pada karakteristik kompetensi yang mencakup: 1) sikap: menerima, menjalankan, menghargai, menghayati, dan mengamalkan, 2) keterampilan: mengamati, menanya, mencoba, menalar, menyajikan, dan mencipta, dan 3) pengetahuan: mengetahui, memahami, menerapkan, menganalisis, mengevaluasi, dan mencipta; b) menggunakan pendekatan saintifik, karakteristik kompetensi sesuai jenjang.

kurikulum 2013 IPS merupakan salah satu mata pelajaran yang mempunyai peranan penting dalam pendidikan. Karena IPS pelajaran yang mempelajari berbagai bidang dari sejarah, ekonomi, politik, teknologi dan seterusnya. Oleh sebab itu, harus mempelajari IPS agar dapat digunakan sebagai sarana untuk memecahkan masalah kehidupan sehari-hari, meskipun banyak orang yang memandang IPS sebagai bidang studi yang paling menjenuhkan. Pada setiap jenjang pendidikan tidak terlepas dari mata pelajaran IPS mulai dari sekolah dasar hingga perguruan tinggi. Pendidikan IPS merupakan salah satu pondasi dari kemampuan sains dan teknologi. Pemahaman terhadap IPS dari kemampuan yang bersifat keahlian sampai kepada pemahaman yang bersifat apresiasif akan berhasil mengembangkan kemampuan yang cukup tinggi. Mengingat pentingnya IPS dalam pengembangan generasi, maka siswa tidak boleh 
dibiarkan jenuh dalam belajar IPS yang dikarenakan menganggap IPS sebagai pelajaran yang menjenuhkan. IPS menjadi mata pelajaran yang paling menjenuhkan oleh sebagian besar siswa, karena dalam memahami materinya memerlukan adanya kejelian berpikir dan wawasan yang luas. Karena IPS dalam pembelajaran mempelajari tentang berbagai ilmu seperti Sejarah, Ekonomi, Politik, Teknologi, Sosiologi, Antropologi, Geografi dan seterusnya. Selain itu, pengamatan yang dilakukan di sekolah dasar pembelajaran masih berpusat pada guru belum melibatkan siswa secara aktif sehingga pembelajaran tidak efektif dan menimbulkan kejenuhan atau membosankan yang disebabkan kurangnya motivasi siswa untuk belajar IPS.

Tujuan pembelajaran IPS, yaitu agar peserta didik mengembangkan pengetahuan dan hasil belajar IPS yang bermanfaat dan dapat diterapkan dalam kehidupan sehari-hari. Berdasarkan taksonomi Bloom, pada jenjang kemampuan pemahaman meliputi tranlasi (kemampuan mengubah simbol dari satu bentuk ke bentuk lain), interpretasi (kemampuan menjelaskan materi), dan ekstrapolasi (kemampuan memperluas arti). Menurut Berns \& Erickson (2001) mengungkapkan bahwa, dalam suatu domain belajar, pemahaman merupakan prasyarat mutlak untuk tingkatan kemampuan kognitif yang lebih tinggi, aplikasi, analisis, sintesis, dan evaluasi.

Salah satu aspek yang mengalami perkembangan dibanding kurikulum sebelumnya adalah penilaian. Pada Kurikulum 2013, penilaian diatur dalam Permendikbud Nomor 66 Tahun 2013 tentang Standar Penilaian Pendidikan meliputi penilaian otentik, penilaian diri, penilaian berbasis portofolio, ulangan harian, ulangan tengah semester, ulangan akhir, ujian tingkat kompetensi, ujian mutu tingkat kompetensi, ujian nasional dan ujian sekolah/madrasah. Penilaian ini merupakan penilaian hasil belajar yang dilakukan oleh pendidik, satuan pendidikan dan pemerintah. Pada Kurikulum 2013, penilaian lebih tegas dan menyeluruh dibanding dengan pelaksanaan penilaian pada Kurikulum
2006. Dalam proses penilaian hasil belajar yang dilakukan oleh pendidik, soal menjadi hal penting yang perlu dikembangakan untuk meningkatkan mutu pendidikan. Arikunto (2001, 57) menyatakan bahwa "sebuah tes dapat dikatakan baik sebagai alat pengukur harus memenuhi persyaratan tes, yaitu memiliki validitas, reliabilitas, obyektivitas, praktikabilitas dan ekonomis".

Berdasarkan kebutuhan dan analisis data melalui wawancara yang telah dilakukan terhadap seorang wali kelas IV di SD N 4 Tejakula bahwa guru kelas masih kesulitan dalam membuat tes yang valid dan reliabel serta kurangnya pengetahuan tentang karakteristik butir soal seperti daya beda, indeks kesukaran, dan pengecoh yang berkualitas baik. Sehingga dalam pembuatan soal guru merasa belum maksimal. Guru juga kesulitan mengetahui penyebab kurangnya semangat siswa dalam mengikuti pembelajaran sehingga kelas menjadi tidak aktif. Kemudian dilanjutkan dengan observasi di Gugus III Kecamatan Tejakula Kabupaten Buleleng. Dari hasil observasi yang diperoleh sebagai berikut. a) Guru tidak mengembangkan soal dan hanya mengandalkan soal yang ada pada buku ajar b) Guru kurang memperhatikan siswa yang terlihat bosan dan lain-lain saat pembelajaran berlangsung. Berdasarkan pemaparan tersebut, maka peneliti terdorong untuk melakukan penelitian dan pengembangan (Research and Development) yang berjudul "PENGEMBANGAN TES HASIL BELAJAR IPS DAN KUESIONER MOTIVASI BELAJAR SISWA KELAS IV SD".

\section{METODE}

Penelitian ini menggunakan model penelitian dan pengembangan pendidikan (educational research and development) yang bertujuan untuk mengembangkan intrumen tes hasil belajar IPS dan kuesioner motivasi belajar kelas IV SD. Desain penelitian ini menggunakan model pengembangan 4D (four-D). Menurut Thiagarajan et al (dalam Trianto,2012) model menelitian dan pengembangan model 4D terdiri dari 4 tahapan, yaitu; define, design, develop, dan disseminate 
atau dapat diadaptasi menjadi 4P, yaitu; pendefinisian, perancangan, pengembangan, dan penyebaran. Subyek pada penelitian pengembangan seperti ini dapat meliputi para ahli dan praktisi, dalam hal ini adalah 2 dosen Pendidikan Dasar dan 3 guru kelas IV Sekolah Dasar. Dalam penelitian ini, ada dua variabel yang digunakan yaitu intrumen tes hasil belajar IPS dan kuesioner motivasi belajar kelas IV SD. Prosedur penelitian dalam pengembangan produk instrumen tes hasil belajar IPS dan kuesioner motivasi belajar kelas IV SD adalah sebagai berikut : (a) define / Analisis kebutuhan dilakukan melalui studi literatur dan studi lapangan/ empirik. Studi literatur dilakukan untuk mengkaji standar isi kurikulum 2013. Adapun kegiatan yang dilakukan pada studi literatur sebagai berikut : Menganalisis standar isi (kompetensi inti dan kompetensi dasar) untuk membuat jaring tema, jaring sub tema sehingga menghasilkan intrumen kemampuan berpikir kritis dan literasi humanistik, Menyususn indikator dan dan ranah kognitif, dan studi lapangan/ empirik dilakukan dengan mengobservasi aktivitas guru dan siswa dalam pelaksanaan pembelajaran di sekolah dasar sesuai dengan kurikulum 2013. (b) Pada tahap perancangan (design) hasil-hasil yang diperoleh dari studi literatur dan studi lapangan digunakan untuk merancang intrumen tes hasil belajar IPS dan kuesioner motivasi belajar kelas IV SD. Pada rancangan draf Intrumen ini kegiatan yang dilakukan adalah menganalisis kurikulum, pemetaan jejaring tema kelas IV untuk mengembangkan prototype intrumen, yang nantinya akan divalidasi oleh ahli dan validasi oleh praktisi untuk mengetahui kelemahan-kelemahan konstruks instrumen tes hasil belajar IPS dan kuesioner motivasi belajar kelas IV SD yang telah dikembangkan dan sesuai dengan masukan yang diberikan, maka dilakukan penyempurnaan untuk mendapatkan draf instrumen tes hasil belajar IPS dan kuesioner motivasi belajar kelas IV SD yaitu : Pengembangan intrumen sesuai dengan validasi ahli, Validitas ahli dilakukan untuk memastikan pengembangan instrument kemampuan berpikir kritis dan literasi humanistik sesuai dengan isi, Validasi produk instrumen oleh praktisi guru senior (ahli kurikulum), dan Revisi produk (Intrumen), (c) Tahap pengembangan (develop) produk akhir dari penelitian dan pengembangan ini adalah instrument tes hasil belajar IPS dan kuesioner motivasi belajar kelas IV SD yang valid, reliabel dan relevan untuk diterapkan dalam pembelajaran (validasi skup terbatas). Hasil pengujian kemudian digunakan untuk revisi sehingga produk memenuhi kriteria kelayakan (secara teoretik) untuk diimplementasi, (d) Thiagarajan (1974: 9) membagi tahap disseminate dalam tiga kegiatan yaitu: validation testing, packaging, diffusion and adoption. Pada tahap validation testing, produk yang sudah direvisi pada tahap pengembangan kemudian diimplementasikan pada sasaran yang sesungguhnya. Pada penelitian pengembangan ini teknik pengumpulan data dapat menggunakan tes objektif dan teknik kuesioner. Tes dan kuesioner digunakan untuk mengukur kelayakan/ validasi dari produk telah dikembangkan. Dalam penelitian ini validitas yang diuji yaitu instrumen tes hasil belajar IPS dan kuesioner motivasi belajar kelas IV SD diuji terlebih validasi oleh 3 praktisi dari guru SD dan 2 Pakar Dosen Pendas. Instrumen disebut valid apabila benarbenar mampu mengukur apa yang semestinya diukur dengan instrumen tersebut (Candiasa, 2010:21). Hasil validasi dari validator dianalisis menggunakan yaitu menghitung CVI (Content Validity Index). CVI digunakan untuk menghitung rata-rata dari keseluruhan nilai CVR untuk komponen instrumen tes hasil belajar IPS dan kuesioner motivasi belajar kelas IV SD. Dalam penelitian ini uji reliabilitas instrumen tes hasil belajar IPS menggunakan formula KR20 sedangkan uji reliabilitas instrumen kuesioner motivasi belajar dilakukan dengan menggunakan teknik formula alpha cronbach. menurut arikunto (2009), rumus alpha cronbach digunakan untuk mencari reliabillitas instrumen yang skornya bukan 1 dan 0 , seperti angket atau soal bentuk uraian. Rumus alpha cronbach sebagai berikut.analisis Content Validity Ratio (CVR) Ketentuan tentang indeks CVR 
menurut Lawshe (1975) sebagai berikut: (a) Saat jumlah responden yang menyatakan setuju atau sangat setuju kurang dari $1 / 2$ total responden maka nilai CVR = - , (b) Saat jumlah responden yang menyatakan setuju atau sangat setuju $1 / 2$ dari total responden maka nilai $\mathrm{CVR}=0$, (c) Saat seluruh responden menyatakan setuju atau sangat setuju maka nilai CVR $=1$ (hal ini diatur menjadi 0,99 disesuaikan dengan jumlah). Karena jumlah responden yang digunakan dalam penelitian ini ada 5 orang maka nilai kritis CVR $=0,99$, (d) Saat jumlah responden yang menyatakan setuju atau sangat setuju lebih dari $1 / 2$ total responden maka nilai $C V R=0-0,99$. Setelah mengidentifikasi setiap sub pertanyaan instrumen dengan menggunakan CVR, maka selanjutnya yaitu menghitung $\mathrm{CVI}$ (Content Validity Index). CVI digunakan untuk menghitung rata-rata dari keseluruhan nilai CVR untuk komponen instrumen tes hasil belajar IPS dan kuesioner motivasi belajar.

\section{HASIL DAN PEMBAHASAN}

1) Laporan uji validitas instrumen tes hasil belajar IPS. Instrumen yang dikembangkan dalam penelitian ini salah satunya adalah instrumen tes hasil belajar IPS. Kemudian instrumen tes hasil belajar IPS. tersebut diuji validasi oleh 5 pakar yaitu 2 ahli dan 3 praktisi (guru). Deskripsi data hasil uji pakar dipaparkan pada tabel berikut. Untuk menghitung validitas content dengan 5 pakar yaitu 2 dosen ahli dan 3 praktisi dari guru menggunakan rumus Lawshe. Perhitung validitas content menggunakan rumus Lawshe dipaparkan pada tabel 1 berikut.

Tabel 1. Table Kerja untuk Menghitung Validitas Content Instrumen Tes Hasil Belajar dengan 5 Pakar Menggunakan Rumus Lawshe

\begin{tabular}{ccccc}
\hline $\begin{array}{c}\text { No } \\
\text { butir }\end{array}$ & Relevan & Tidak Relevan & CVR & Status soal \\
\hline 1 & 5 & 0 & 1 & Terpakai \\
2 & 4 & 1 & 0,6 & Terpakai \\
3 & 4 & 1 & 0,6 & Terpakai \\
4 & 5 & 0 & 1 & Terpakai \\
5 & 5 & 0 & 1 & Terpakai \\
6 & 5 & 0 & 1 & Terpakai \\
7 & 4 & 1 & 0,6 & Terpakai \\
8 & 5 & 0 & 1 & Terpakai \\
9 & 4 & 1 & 0,6 & Terpakai \\
10 & 4 & 1 & 0,6 & Terpakai \\
11 & 4 & 1 & 0,6 & Terpakai \\
12 & 4 & 1 & 0,6 & Terpakai \\
13 & 4 & 1 & 0,6 & Terpakai \\
14 & 5 & 0 & 1 & Terpakai \\
15 & 4 & 1 & 0,6 & Terpakai \\
16 & 3 & 2 & 0,2 & Terpakai \\
17 & 4 & 1 & 0,6 & Terpakai \\
18 & 4 & 1 & 0,6 & Terpakai \\
19 & 5 & 0 & 1 & Terpakai \\
20 & 3 & 2 & 0,2 & Terpakai \\
21 & 3 & 2 & 0,2 & Terpakai \\
22 & 5 & 0 & 1 & Terpakai \\
23 & 5 & 0 & 1 & Terpakai \\
24 & 5 & 0 & 1 & Terpakai \\
25 & 5 & 0 & 0,6 & Terpakai \\
26 & 4 & 1 & 0,6 & Terpakai \\
27 & 4 & 1 & 0,2 & Terpakakai \\
\hline 28 & 3 & 2 & & \\
\hline & & & 1 & \\
\hline
\end{tabular}




\begin{tabular}{lllll}
\hline 29 & 3 & 2 & 0,2 & Terpakai \\
30 & 3 & 2 & 0,2 & Terpakai \\
31 & 4 & 1 & 0,6 & Terpakai \\
32 & 3 & 2 & 0,2 & Terpakai \\
33 & 4 & 1 & 0,6 & Terpakai \\
34 & 3 & 2 & 0,2 & Terpakai \\
35 & 3 & 2 & 0,2 & Terpakai \\
\hline
\end{tabular}

Langkah-langkah Perhitungan Validitas Instrumen hasil belajar IPS sebagai berikut:

a. Menghitung nilai CVR dengan

rumus Lawshe sebagai berikut.

$C V R=\frac{2 M p}{M}-1$

Keterangan:

$\mathrm{CVR}=$ content validity rasio

$\mathrm{Mp}=$ banyak pakar yang menjawab penting/Relevan M = banyaknya pakar yang memvalidasi

Contoh menghitung butir No :

1) Perhitungan untuk butir No.1 (diketahui $\mathrm{Mp}=5, \mathrm{M}=5$ ) setelah melakukan perhitungan, hasilnya adalah: $\quad C V R=\frac{2.5}{5}-1=1 \quad$ dan dinyatakan valid

2) Perhitungan untuk butir No.2 (diketahui $\mathrm{Mp}=4, \mathrm{M}=5$ ) setelah melakukan perhitungan, hasilnya adalah: $\quad C V R=\frac{2.4}{5}-1=0,6 \quad$ dan dinyatakan valid

b. Menghitung Content Validity Index (CVI)

$C V I=\frac{\sum C V R}{k}$
$C V I=\frac{21,2}{35}=0,60$

Keterangan:

$\mathrm{CVI}=$ Content Validity Index

$\Sigma$ CVR = Jumlah Content Validity Ratio

$\mathrm{k}$ = Banyaknya butir

Berdasarkan hasil uji validitas content dengan 5 pakar yakni 2 dosen ahli dan 3 praktisi (guru) diperoleh hasil perhitungan dengan rumus Lawshe, diperoleh content validity index sebesar 0,60 . Hal ini berarti, yang diujikan termasuk ke dalam kriteria validitas tinggi. Maka dapat disimpulkan bahwa tes hasil belajar IPS dapat dilanjutkan.

2) Laporan uji validitas instrumen kuesioner motivasi belajar. Instrumen yang dikembangkan dalam penelitian ini adalah instrumen kemampuan pemecahan masalah instrumen kemampuan pemecahan masalah diuji validasi oleh 5 pakar yaitu 2 ahli dan 3 praktisi (guru).

Untuk menghitung validitas content dengan 5 pakar yaitu 2 dosen ahli dan 3 praktisi dari guru menggunakan rumus Lawshe. Perhitung validitas content menggunakan rumus Lawshe dipaparkan pada tabel 2. berikut

Tabel 2. Table Kerja untuk Menghitung Validitas Content Instrumen Kuesioner Motivasi Belajar dengan 5 Pakar Menggunakan Rumus Lawshe

\begin{tabular}{ccccc}
\hline No butir & Relevan & Tidak Relevan & CVR & Status soal \\
\hline 1 & 5 & 0 & 1 & Terpakai \\
2 & 5 & 0 & 1 & Terpakai \\
3 & 5 & 0 & 1 & Terpakai \\
4 & 5 & 0 & 1 & Terpakai \\
5 & 5 & 0 & 1 & Terpakai \\
6 & 5 & 0 & 1 & Terpakai \\
7 & 5 & 0 & 1 & Terpakai \\
8 & 5 & 0 & 1 & Terpakai \\
9 & 5 & 0 & 1 & Terpakai \\
10 & 5 & 0 & 1 & Terpakai \\
\hline
\end{tabular}




\begin{tabular}{lllll}
\hline 11 & 5 & 0 & 1 & Terpakai \\
12 & 5 & 0 & 1 & Terpakai \\
13 & 5 & 0 & 1 & Terpakai \\
14 & 5 & 0 & 1 & Terpakai \\
15 & 5 & 0 & 1 & Terpakai \\
16 & 5 & 0 & 1 & Terpakai \\
17 & 5 & 0 & 1 & Terpakai \\
18 & 5 & 0 & 1 & Terpakai \\
19 & 5 & 0 & 1 & Terpakai \\
20 & 5 & 0 & 1 & Terpakai \\
21 & 5 & 0 & 1 & Terpakai \\
22 & 5 & 0 & 1 & Terpakai \\
23 & 5 & 0 & 1 & Terpakai \\
24 & 5 & 0 & 1 & Terpakai \\
25 & 5 & 0 & 1 & Terpakai \\
26 & 5 & 0 & 1 & Terpakai \\
27 & 5 & 0 & 1 & Terpakai \\
28 & 5 & 0 & 1 & Terpakai \\
29 & 5 & 0 & 1 & Terpakai \\
30 & 5 & 0 & 1 & Terpakai \\
31 & 5 & 0 & 1 & Terpakai \\
32 & 5 & 0 & 1 & Terpakai \\
33 & 5 & 0 & 1 & Terpakai \\
34 & 5 & 0 & 1 & Terpakai \\
35 & 5 & 0 & 1 & Terpakai \\
& & & 35 & \\
\hline & & $0 V R$ & & \\
\hline
\end{tabular}

Langkah-langkah Perhitungan Validitas Instrumen hasil Motivasi Belajar sebagai berikut:

a. Menghitung nilai CVR dengan rumus Lawshe sebagai berikut.

$C V R=\frac{2 M p}{M}-1$

Keterangan:

$\mathrm{CVR}=$ content validity rasio

$\mathrm{Mp}=$ banyak pakar yang menjawab penting/Relevan

$\mathrm{M}=$ banyaknya pakar yang memvalidasi

Contoh menghitung butir No :

1) Perhitungan untuk butir No.1 (diketahui $\mathrm{Mp}=5, \mathrm{M}=5$ ) setelah melakukan perhitungan, hasilnya adalah: $\quad C V R=\frac{2.5}{5}-1=1 \quad$ dan dinyatakan valid

b. Menghitung Content Validity Index (CVI)

$$
C V I=\frac{\sum C V R}{k} C V I=\frac{35}{35}=1
$$

Keterangan:

$\mathrm{CVI}=$ Content Validity Index $\sum$ CVR = Jumlah Content Validity Ratio

$\mathrm{k}$ = Banyaknya butir

Berdasarkan hasil uji validitas content dengan 5 pakar yakni 2 dosen ahli dan 3 praktisi (guru) diperoleh hasil perhitungan dengan rumus Lawshe, diperoleh content validity index sebesar 0,60 . Hal ini berarti, yang diujikan termasuk ke dalam kriteria validitas tinggi. Maka dapat disimpulkan bahwa kuesioner motivasi belajar dapat dilanjutkan. Sejalan dengan Kadek Sembah (2012) Dengan instrumen penelitian yang valid maka hasil dari pengukuran kualitas media pembelajaran dipertanggungjawabkan

3) Laporan uji reliabilitas instrumen tes hasil belajar IPS. Instrumen yang digunakan dalam penelitian ini harus memenuhi syarat reliabel. Instrumen yang reliabel adalah instrumen yang apabila digunakan beberapa kali untuk mengukur obyek yang sama, akan menghasilkan data yang sama (Sugiyono, 2008). Instrumen yang baik adalah instruen yang dapat dengan konsisten memberikan data yang sesuai dengan kenyataannya. 
Karena bentuk instrumennya adalah tes hasil belajar IPS dengan rentang skor 0-1, maka untuk mencari reabilitas kuesioner tersebut dapat digunakan rumus yaitu.

$$
r_{1.1}=\left(\frac{n}{n-1}\right)\left(\frac{S_{t}^{2} \sum p q}{S_{t}^{2}}\right)
$$

(Candiasa, 2010:53)

Keterangan :

$$
\begin{aligned}
r_{1.1}= & \text { koefisien reliabilitas perangkat } \\
& \text { tes } \\
\mathrm{n}= & \text { banyak butir } \\
\mathrm{S}_{\mathrm{t}}= & \text { standar deviasi skor total } \\
\mathrm{q}= & \text { proporsi siswa yang menjawab } \\
& \text { benar untuk tiap-tiap butir } \\
\mathrm{q}= & \begin{array}{l}
\text { proporsi siswa yang menjawab } \\
\text { salah untuk tiap-tiap butir }
\end{array}
\end{aligned}
$$

Untuk menentukan tingkat realiabilitas tes digunakan kriteria yaitu:

$$
\begin{array}{lll}
0,80<r_{1.1} \leq & = & \text { derajat reliabilitas } \\
1,00 & \text { sangat tinggi; } \\
0,60<r_{1.1} \leq & = & \text { derajat reliabilitas } \\
& \text { tinggi; } \\
0,80 & = & \text { derajat reliabilitas } \\
0,40<r_{1.1} \leq & & \text { cukup; } \\
0,60 & = & \text { derajat reliabilitas } \\
0,20<r_{1.1} \leq & & \text { rendah; } \\
0,40 & = & \text { derajat reliabilitas } \\
0,00<r_{1.1} \leq & \text { sangat rendah; } &
\end{array}
$$

(Koyan,2011:136)

Ringkasan hasil perhitungan uji reliabilitas perangkat tes hasil belajar IPS terdapat pada tabel 3. sebagai berikut.

Tabel 3. Ringkasan Hasil Perhitungan Reliabilitas pada Tes Hasil Belajar IPS

$\begin{array}{cc}\sum_{\mathrm{pq}} & 3,52 \\ \mathrm{St} & 19,80 \\ \mathrm{r} 1.1 & 0,85\end{array}$

Status Sangat Tinggi

Perhitungan reliabilitas tes hasil belajar IPS menggunakan rumus KR 20 yaitu:

$$
\begin{aligned}
& r_{1.1}=\left(\frac{n}{n-1}\right)\left(\frac{S_{t}^{2} \sum p q}{S_{t}^{2}}\right) \\
& r_{1.1}=\left(\frac{n}{n-1}\right)\left(\frac{19,80-0,00}{19,80}\right) \quad=0,85
\end{aligned}
$$

4) Laporan uji reliabilitas instrumen kuesioner motivasi belajar. Instrumen yang digunakan dalam penelitian ini harus memenuhi syarat reliabel. Instrumen yang reliabel adalah instrumen yang apabila digunakan beberapa kali untuk mengukur obyek yang sama, akan menghasilkan data yang sama (Sugiyono, 2008). Instrumen yang baik adalah instruen yang dapat dengan konsisten memberikan data yang sesuai dengan kenyataannya.

Karena bentuk instrumennya adalah kuesioner motivasi belajar dengan rentang skor 1-5, maka untuk mencari reabilitas kuesioner tersebut dapat digunakan teknik formula alpha cronbach sebagai berikut.

$$
\begin{array}{ll}
\mathrm{k} & =35 \\
\sum \sigma \frac{2}{b} & =1,67 \\
\sigma_{\frac{2}{t}} & =4,59
\end{array}
$$

Masukan data kedalam rumus:

$$
\begin{aligned}
& r 11=\left[\frac{k}{k-1}\right]\left[1-\frac{\sum \sigma \frac{2}{b}}{\sigma \frac{2}{t}}\right] \\
& r 11=\left[\frac{35}{35-1}\right]\left[1-\frac{1,67}{4,59}\right] \\
& r 11=[1,02][0,635] \\
& r 11=0,654
\end{aligned}
$$

Keterangan:

$$
\begin{array}{ll}
r_{11} & =\begin{array}{l}
\text { Koefisien reliabilitas } \\
\text { perangkat tes }
\end{array} \\
\Sigma \sigma_{i}^{2} & =\begin{array}{l}
\text { Jumlah varian skor tiap } \\
\text { butir }
\end{array} \\
\sum \sigma_{t}^{2} & =\text { Varian total } \\
N & =\begin{array}{l}
\text { Jumlah butir yang valid } \\
\text { Kriteria }
\end{array}
\end{array}
$$

Kriteria:

$r \leq 0,20$

$$
\begin{array}{ll}
0,20<r \leq 0,40 & \text { Rendah } \\
0,40<r \leq 0,60 & \text { Sedang } \\
0,60<r \leq 0,80 & \text { Tinggi } \\
0,80<r \leq 1,00 & \text { Sangat tinggi }
\end{array}
$$

Berdasarkan hasil uji reliabilitas instrument kuesioner motivasi belajar dengan 5 pakar menggunakan rumus alpha cronbach mendapatkan hasil 
sebesar $r 11=0,654$. Hal ini berarti, instrumen kuesioner motivasi belajar yang dikembangkan mempunyai kriteria reliabilitas tinggi.

Tabel 4. Ringkasan Hasil Perhitungan Reliabilitas pada Motivasi Belajar

\begin{tabular}{cc}
\hline $\mathrm{k}$ & 35 \\
$\sum \sigma_{i}^{2}$ & 1,67 \\
$\sum \sigma_{t}^{2}$ & 4,59 \\
$\mathrm{r} 1.1$ & 0,654 \\
Status & Tinggi \\
\hline
\end{tabular}

\section{PENUTUP}

Berdasarkan laporan hasil penelitian seperti yang telah dipaparkan pada bagian sebelumnya, maka dapat disimpulkan beberapa hasil penelitian sebagai berikut.

1. Instrumen tes hasil belajar IPS yang dikembangkan memenuhi syarat validitas konten dengan nilai 0.60 dengan kriteria sangat tinggi sehingga digunakan untuk mengetahui kemampuan kognitif IPS siswa kelas IV SD.

2. Instrumen validitas kuesioner motivasi belajar yang dikembangkan memenuhi syarat validitas konten dengan nilai 1.00 dengan kategori sangat baik sehingga sangat layak digunakan untuk mengetahui seberapa besar siswa termotivasi dalam proses pembelajaran.

3. Instrumen tes hasil belajar IPS yang dikembangkan memenuhi syarat reliabilitas expert dengan nilai 0.85 dengan kategori sangat tinggi sehingga layak digunakan untuk mengetahui kemampuan kognitif IPS siswa kelas IV SD.

4. Instrumen kuesioner motivasi belajar yang dikembangkan memenuhi syarat reliabilitas expert dengan nilai 0.64 dengan kategori tinggi sehingga layak digunakan untuk mengetahui seberapa besar siswa termotivasi dalam proses pembelajaran.

Mengacu pada rumusan masalah dan didukung oleh laporan hasil penelitian dalam penelitian ini, dapat diajukan saran sebagai berikut.

Adapun saran yang disampaikan dalam penelitian pengembangan instrumen kemampuan hasil belajar IPS dan motivasi belajar sebagai berikut.

a. Saran pemanfaatan untuk guru, disarankan untuk memanfaatkan instrumen hasil belajar IPS sebagai alat penilaian dalam proses pembelajaran kepada siswanya untuk mengningkatkan hasil belajar siswa pada pelajaran IPS dan menggunakan instrumen motivasi belajar untuk meningkatkan motivasi belajar siswa di kelas.

b. Saran desiminasi, disarankan untuk menyebarluaskan produk di sekolah dengan menyerahkan instrumen hasil belajar IPS dan motivasi belajar kepada guru di tempat uji produk serta menyebarluaskan melalui publikasi jurnal.

c. Saran pengembangan produk lebih lanjut, disarankan untuk mengembangkan instrumen hasil belajar IPS dan motivasi belajar dengan materi lain serta di kelas yang berbeda.

\section{DAFTAR RUJUKAN}

Pembelajaran. Bandung: Alfabeta.

Arikunto, S. (2001). Dasar-Dasar Evaluasi Pendidikan.Jakarta: Bumi Aksara,

Candiasa, I Made. 2010. Pengujian Instrumen Penelitian Disertai Aplikasi ITEMAN dan BIGSTEPS. Singaraja: Unit Universitas Pendidikan Ganesha.

Bern, Robert G. dan Patricia M. Erickson. 2001. Contextual Teaching and Learning: Preparing Students for the New Economy. Tersedia pada http://eric.ed.gov/?id=ED452376, diakses pada tanggal 1 Mei 2019.

Koyan, I Wayan. 2011. Asesmen Dalam Pendidikan. Singaraja: Universitas Pendidikan Ganesha Press.

Sembah, Kadek. 2012. Pengembangan Media Pembelajaran Berbasis Komputer Dengan Microsoft Excel Yang Berorientasi Teori Van Hiele 
Pada Bahasan Trigonometri Kelas X Sma Untuk Meningkatkan Prestasi Dan Motivasi Belajar Matematika Siswa.

http://oldpasca.undiksha.ac.id/e-

journal/index.php/JPM/article/view/4 45/237. Diakses Pada 5 Juli 2020

Sugiyono. 2008. Metode Penelitian Kuantitatif Kualitatif dan R\&D. Bandung : ALFABETA

Thiagarajan, Sivasailam, dkk. (1974). Instructional Development for Training Teachers of Exceptional Children. Washinton DC: National Center for Improvement Educational System 